shorter essays and more clinical relevance. With regard to the Membership, the suggestion that the trainee should be observed interviewing the patient was strongly rejected. The trainees were, however, in favour of the use of videotaped short cases together with a long case. There was an overwhelming request for more detailed feedback on examination performance, and for greater standardization between examiners.

It was interesting that the additional comments received with the questionnaires were not particularly critical of the examination itself, but were more critical of the preparatory training. The trainees did not appear to be asking for 'spoonfeeding'-indeed, many successfully negotiated the hurdle with few apparent facilities. The main criticism was not directed towards the lack of academic teaching-journal clubs, case presentations, etc-but rather at the lack of guidance by consultants in recognizing psychopathology, interviewing and assessing patients and preparing formula-

\section{Under Discussion}

The old Board of Control used to review all compulsory orders, and could discharge certified patients if it thought fit. It supervised not only the civil liberties but every aspect of the care of patients, from the provision of sufficient lavatories and enough food to the employment of adequate staff. It was a national civil service body that watched the work of the county mental hospitals and other institutions and tried to bring them all to a common standard of humane treatment. When the hospitals were taken away from the local authorities and made part of the NHS, and when in the brave new world of 1959 psychiatric patients were henceforth to be treated like general hospital patients and there were great hopes that the institutions would wither away and Community Care rise in their place, the Board was abolished.

It had become somewhat fossilised, and people forgot that many of its activities had been given to it as a cure of old abuses, which might still recur. And, of course, some of them did: Ely, Whittingham, St Augustine's, Normansfield, etc. The public inquiries into these places have done a good deal to lower psychiatry and psychiatric nursing in public estimation, and they have made the job correspondingly more difficult to do. If the Board of Control had still existed it would have been pressurising the Regional Health Authorities at a much earlier stage to put things right, and if in the end it still came to a public row, responsibility would have been seen to be with the regional and national administration instead of with local nursing and medical staff. Abolition of the Board was a mistake: what was needed in tions. There was also a request for some form of continuous assessment in addition to the Membership examination with regular feedback from consultants and tutors.

It would seem that the preoccupation with the examination itself and with training approval has diverted attention away from the importance of the role of individual consultants in clinical teaching. The examination undoubtedly requires modification, and the setting up of a working party to the end should be a priority (Examination Forum, Bulletin, July 1980). After a decade of doubt and criticism regarding the examination, the time may hopefully come when the MRCPsych will be accepted not as ultimate proof of psychiatric competence but as a necessary minimal requirement for higher psychiatric training. Modifying the examination will not in itself, however, improve training. If such improvement is to be effected, the role of individual consultants must be recognized and encouraged.
1959 was a re-designing and updating of its function, and what may be needed now is some similar watchdog-a Mental Health or Mental Treatment Commission, or some such title.

So at least is the view of some members of the College, who are discussing proposals which might be put into the new Mental Health Bill which the Government plans to bring forward soon, perhaps in the next session. They see both a national commission and some regional commissions under a legal chairman, with members serving full-time for five or seven years, appointed by the Lord Chancellor and independent of the Secretary of State, and representing social work, psychology, nursing and a preponderance of psychiatry, especially forensic psychiatry, mental handicap and psychogeriatrics. The commissions might be aided by panels of psychiatrists to give second specialist opinions in certain cases. They would have wide powers of inspection of standards of care and practice in relation to detained patients everywhere, and would review and monitor all Orders and all treatments given without consent. They would visit hospitals and private institutions to interview patients and investigate complaints, and they would give advice to hospitals and issue regular reports on their work.

None of this is College policy-as yet. The Public Policy Committee and the Executive and Finance Committee hope to finalise a brief discussion document by the end of the year which will be published in the Bulletin. It is literally under discussion, but 1981 may see some firm recommendations. 